\title{
Extraction and Separation Study of Mo(VI) and W(VI) using organophosphorous extractant
}

\author{
D. V. Chavan, S. D. Pawar* \\ Department of Chemistry, University of Mumbai, Lokmanya Tilak Bhavan, Vidyanagari, \\ Santacruz (E), Mumbai - 400 098. India \\ *E-mail address: sureshpawar2004@gmail.com
}

\begin{abstract}
Organophosphorous extractant, Cyanex-923, has been used for the extraction and separation of $\mathrm{Mo}(\mathrm{VI})$ and $\mathrm{W}(\mathrm{VI})$ is described. The extraction of the metal ions is studied as the function of several parameters such as effect of $\mathrm{pH}$, effect of reagent concentration, stripping agents, diluents study and effect of diverse ion. It was observed that Cyanex-923 extracts $\mathrm{Mo}(\mathrm{VI})$ at $\mathrm{pH}$ 2.5-4.5 while $\mathrm{W}(\mathrm{VI})$ was extracted at $\mathrm{pH}$ 0.5-1.5. The extracted $\mathrm{Mo}(\mathrm{VI})$ was stripped back using $0.1 \mathrm{M} \mathrm{NaOH}$, while $\mathrm{W}(\mathrm{VI})$ was stripped back using $1.0 \mathrm{M}\left(\mathrm{NH}_{4}\right)_{2} \mathrm{CO}_{3}$. The stoichiometry of the extracted species of $\mathrm{Mo}(\mathrm{VI})$ and W(VI) was determined on the basis of slope analysis method. Based on the results sequential methods of separation of both the metals were developed.
\end{abstract}

Keywords: Mo(VI); W(VI); Extraction; Diluents; multicomponent separation

\section{INTRODUCTION}

Tungsten ores mainly wolframite and scheelite, contain several metals as impurities which must be removed prior to recovery of tungsten. Among these impurities molybdenum are undesirable impurity when tungsten is used to manufacture lamp filaments, as it darkens the globe and shortens the life of filament due to its volatilization [1].

Among various extractants such as Alamine 336, MIBK, D2EHPA and TBP [2] are being used in the recovery and separation of tungsten and molybdenum, the tertiary amines have been studied most extensively. The mechanism of extracting tungsten by amines from sulfuric acid medium has also been studied [3-4]. However, the separation of tungsten from molybdenum by using amines as extractants is difficult because of the similar behaviour of these two elements and their compounds. In the proceedings of ISEC'74, Esnault proposed a new process for separating tungsten from molybdenum by using D2EHPA as extractant, by which molybdenum is first preferentially extracted; subsequently tungsten is extracted by amines [5]. Large amounts of tungsten present in solution will seriously affect the extraction of molybdenum; therefore the application of this process is limited. The extraction of Mo(VI) from hydrochloric and perchloric acid media with TBP was also studied [6-7]. Various oxime based extractants, such as LIX 84, L1X 63 and LIX 984N have been proposed as suitable reagents for extraction of Molybdenum [8-11].

In the present work liquid-liquid extraction and separation of Mo(VI) and W(VI) with organophosphorous extractant, Cyanex-923 in toluene has been carried out in $\mathrm{pH}$ range. 


\section{EXPERIMENTAL}

\subsection{Apparatus and reagents}

The extractant, Cyanex 923 supplied by Cytec Inc., Canada, were used without further purification. Known amount of sodium molybdate and sodium tungstate were dissolved in minimum amount of $\mathrm{HCl}$ and diluted to one litre with double distilled water and standardised by known method [12]. All other chemicals used were of analytical grade, Elico model L1-120 pH meter with combined electrode was used for $\mathrm{H}^{+}$ion concentration studies and GBC 911A UV-visible spectrophotometer with $10 \mathrm{~mm}$ cortex quartz cuvette was used for absorbance measurements.

\subsection{Procedure}

An aliquot of $\mathrm{Mo}(\mathrm{VI})$ and $\mathrm{W}(\mathrm{VI})$ containing $50 \mu \mathrm{g}$ were taken in two different separating funnels. In the case of Mo(VI) the $\mathrm{pH}$ was maintained at 2.5 while for extraction of $\mathrm{W}(\mathrm{VI})$ the $\mathrm{pH}$ was maintained at 1.0. Thereafter the aqueous phase was equilibrated with 10 $\mathrm{cm}^{3}$ of Cyanex 923 in toluene for the required period of shaking of 5 mins. The Mo(VI) and $\mathrm{W}(\mathrm{VI})$ ions from the organic phase of extractant were stripped back with $0.1 \mathrm{M} \mathrm{NaOH}$ and $0.5 \mathrm{M}\left(\mathrm{NH}_{4}\right)_{2} \mathrm{CO}_{3}$ respectively. The amount of metal ions extracted was determined by the known methods [13].

\section{RESULTS AND DISCUSSIONS}

\subsection{Effect of pH}

The effect of $\mathrm{pH}$ on the percentage extraction of $\mathrm{Mo}(\mathrm{VI})$ and $\mathrm{W}(\mathrm{VI})$ was studied in the $\mathrm{pH}$ range with Cyanex 923 in toluene (Fig.1). It was found that cyanex-923 extracted Mo(VI) and $\mathrm{W}(\mathrm{VI})$ in the $\mathrm{pH}$ range 2.5-4.5 and 0.5-1.5 respectively. Hence all the extractions were carried out at $\mathrm{pH} 2.5$ for $\mathrm{Mo}(\mathrm{VI})$ and $\mathrm{pH} 1.0$ for $\mathrm{W}(\mathrm{VI})$ with cyanex-923. 


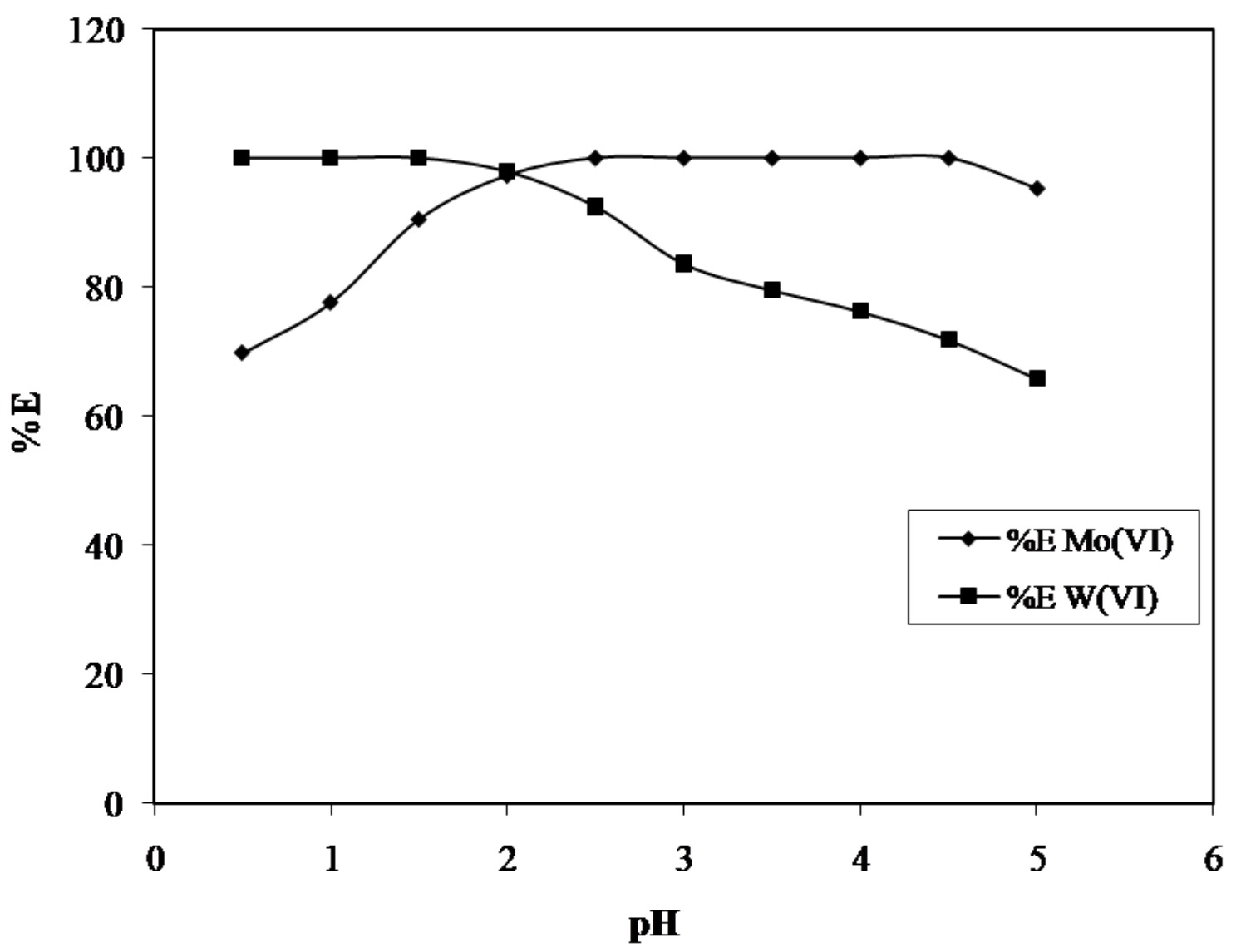

Fig.1.Effect of pH on percentage extraction of Mo(VI) and W(VI) with Cyanex923 in toluene.

\subsection{Effect of reagent concentration}

Extraction of $\mathrm{Mo}(\mathrm{VI})$ and $\mathrm{W}(\mathrm{VI})$ was also carried out by varying the reagent concentration $\left(1 \times 10^{-2}\right.$ to $\left.1.25 \times 10^{-4} \mathrm{M}\right)$ while keeping other parameters like $\mathrm{pH}$, period of equilibration, diluent and temperature constant. Extraction was found to increase with increase in reagent concentration. The extraction of $\mathrm{Mo}(\mathrm{VI})$ and $\mathrm{W}(\mathrm{VI})$ was quantitative with $5 \times 10^{-3}$ M Cyanex 923 in toluene.

\subsection{Effect of Diluents}

Various organic diluents like toluene, chloroform, carbon tetrachloride, benzene, cyclohexane, $\mathrm{n}$-hexane and xylene were employed for extraction of both the metal ions. It was found that with cyanex-923 for both the metal ions the extraction was quantitative with all the above diluents except with chloroform (96.3\%). Toluene is preferred as diluent for the extractant because of its better phase separation. 


\subsection{Effect of Various Stripping Agents}

Both the metal ions were stripped out from their loaded organic phases with different strength mineral acids like $\mathrm{HCl}, \mathrm{HNO}_{3}$ and $\mathrm{H}_{2} \mathrm{SO}_{4}$ and bases like $\mathrm{NaOH}$ and $\left(\mathrm{NH}_{4}\right)_{2} \mathrm{CO}_{3}$. $\mathrm{Mo}(\mathrm{VI})$ was quantitatively stripped with 0.1 and $0.2 \mathrm{M} \mathrm{NaOH}$, while $0.5 \mathrm{M}$ and $1.0 \mathrm{M}$ $\left(\mathrm{NH}_{4}\right)_{2} \mathrm{CO}_{3}$ was found to strip W(VI) with cyanex 923 respectively. Therefore $0.1 \mathrm{M} \mathrm{NaOH}$ and $0.5 \mathrm{M}\left(\mathrm{NH}_{4}\right)_{2} \mathrm{CO}_{3}$ were preferred as stripping agents for $\mathrm{Mo}(\mathrm{VI})$ and $\mathrm{W}(\mathrm{VI})$ respectively (Table-1).

Table 1. Effect of stripping agent on percentage recovery of Mo(VI) and W(VI) with Cyanex 923.

\begin{tabular}{|c|c|c|c|c|}
\hline \multicolumn{5}{|c|}{ Mo $(\mathrm{VI})-50 \mu \mathrm{g}, \mathrm{W}(\mathrm{VI})-50 \mu \mathrm{g}$} \\
\hline Acids & $1.0 \mathrm{M}$ & $2.0 \mathrm{M}$ & $3.0 \mathrm{M}$ & $4.0 \mathrm{M}$ \\
\hline $\mathrm{HCl}$ & 10.3 & 18.9 & 20.2 & 15.4 \\
\hline $\mathrm{HNO}_{3}$ & 39.1 & 48.9 & 56.2 & 51.2 \\
\hline $\mathrm{H}_{2} \mathrm{SO}_{4}$ & 30.3 & 35.3 & 39.6 & 40.3 \\
\hline $\mathrm{HClO}_{4}$ & 10.3 & 14.9 & 18.3 & 21.1 \\
\hline Base & $0.1 \mathrm{M}$ & $0.2 \mathrm{M}$ & - & - \\
\hline $\mathrm{NaOH}$ & 99.9 & 99.9 & - & - \\
\hline Base & $0.1 \mathrm{M}$ & $0.5 \mathrm{M}$ & $1.0 \mathrm{M}$ & - \\
\hline$\left(\mathrm{NH}_{4}\right)_{2} \mathrm{CO}_{3}$ & 93.5 & 97.9 & 99.9 & - \\
\hline
\end{tabular}

\begin{tabular}{|c|c|c|c|c|}
\hline \multirow{2}{*}{ Acids } & \multicolumn{4}{|c|}{ \% Recovery of Mo(VI) from metal loaded organic phase } \\
\cline { 2 - 5 } & $\mathbf{1 . 0} \mathbf{M}$ & $\mathbf{2 . 0} \mathbf{M}$ & $\mathbf{3 . 0} \mathbf{~ M}$ & $\mathbf{4 . 0} \mathbf{~ M}$ \\
\hline $\mathrm{HCl}$ & 8.7 & 10.6 & 17.9 & 12.1 \\
\hline $\mathrm{HNO}_{3}$ & 36.0 & 39.2 & 40.7 & 41.3 \\
\hline $\mathrm{H}_{2} \mathrm{SO}_{4}$ & 32.4 & 34.2 & 34.7 & 33.2 \\
\hline $\mathrm{HClO}_{4}$ & 8.3 & 12.2 & 18.9 & 24.5 \\
\hline Base & $\mathbf{0 . 1} \mathbf{M}$ & $\mathbf{0 . 2} \mathbf{M}$ & - & - \\
\hline $\mathrm{NaOH}$ & 1.1 & 0.9 & - & - \\
\hline $\mathrm{Base}$ & $\mathbf{0 . 1} \mathbf{M}$ & $\mathbf{0 . 5} \mathbf{M}$ & $\mathbf{1 . 0} \mathbf{M}$ & - \\
\hline$\left(\mathrm{NH}_{4}\right)_{2} \mathrm{CO}_{3}$ & 95.4 & 99.9 & 99.9 & - \\
\hline
\end{tabular}

\subsection{Nature of Extracted Species}

It was necessary to evaluate the distribution coefficient (D) while varying the extractant concentration to ascertain the nature of extracted species. The composition of the extracted species was first ascertained from graph of $\log \mathrm{D}$ versus $\log \mathrm{R}$ at fixed $\mathrm{pH}$ (Fig. 2). The slopes obtained are 2.14 and 2.04 with Cyanex 923 in toluene for Mo(VI) and W(VI) respectively. Hence the probable compositions of the extracted species of Mo(VI) and W(VI) is 1:2. The probable species extracted in the organic phase is $\mathrm{MoO}_{2} \mathrm{Cl}_{2}$. $2 \mathrm{Cyanex}-923$ and $\mathrm{WO}_{2} \mathrm{Cl}_{2}$. 2Cyanex-923 [14]. 


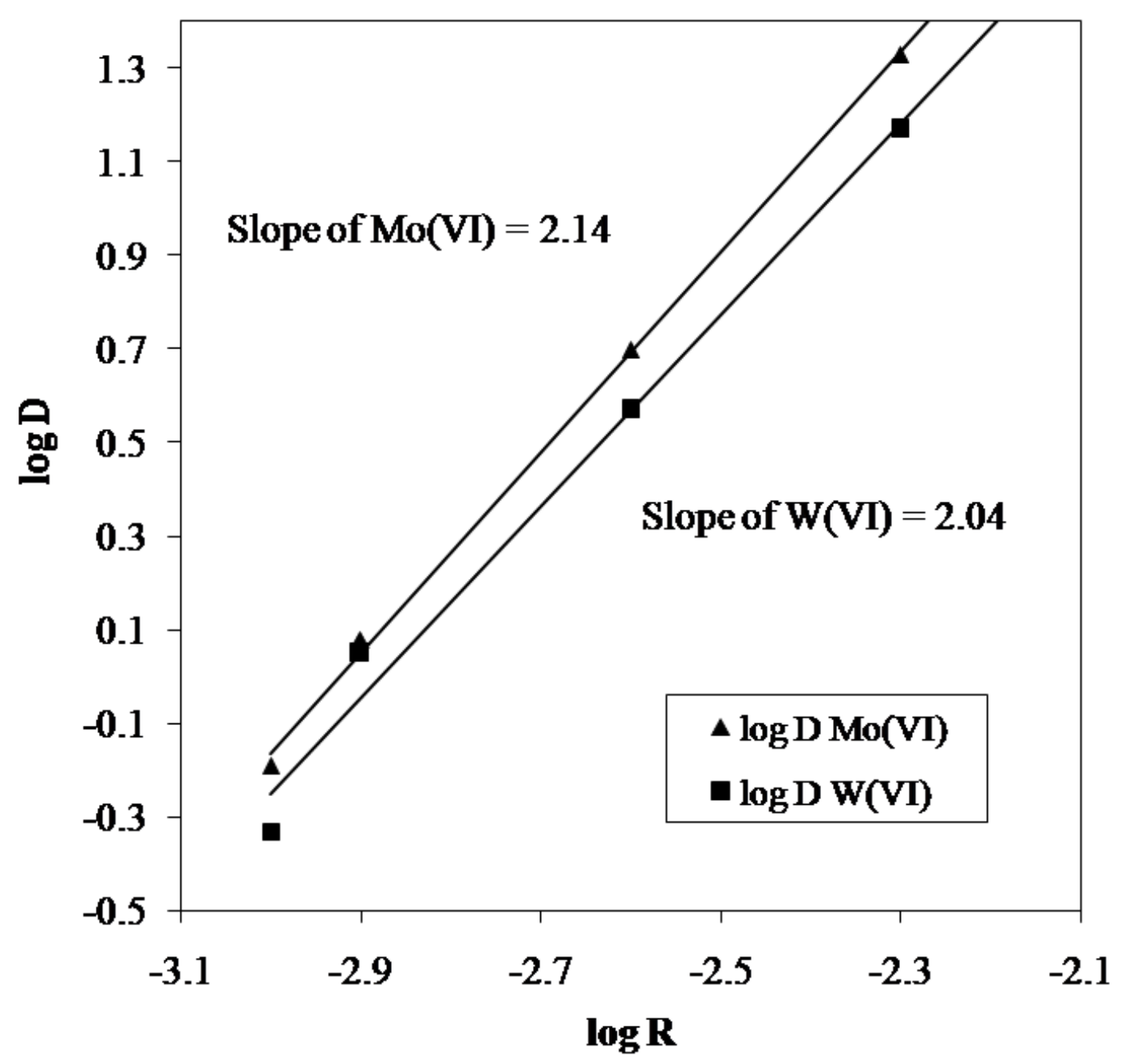

\section{Fig.2.Effect of Reagent concentration on Distribution ratio of Mo(VI) and W(VI).}

\subsection{Effect of Diverse Ion}

The effect of various diverse ion on the extraction of Mo(VI) and W(VI) was studied with Cyanex-923 reagent (Table-2,3). The tolerance limit of individual foreign ions was set so that error in percentage recovery was not more than $\pm 2 \%$. It was found that E.D.T.A, di-Natartrate and $\mathrm{Os}^{+8}$ highly interfere during the extraction of $\mathrm{Mo}(\mathrm{VI})$ while EDTA, $\mathrm{Fe}^{3+}$ and $\mathrm{As}^{3+}$ highly interfere during the extraction of W(VI). Alkali and alkaline earth metals are highly tolerated during extraction of both metal ions. 
Table 2. Effect of Various Diverse Ions on the Extraction of Mo(VI) with Cyanex 923.

\begin{tabular}{|c|c|}
\hline Foreign Ions & Tolerance limit \\
\hline $\mathrm{Na}^{+}, \mathrm{K}^{+}, \mathrm{Li}^{+}, \mathrm{Mg}^{2+}, \mathrm{Ca}^{2+}, \mathrm{SO}_{4}{ }^{2-}$ & $1: 28$ \\
\hline $\mathrm{Al}^{3+}, \mathrm{Be}^{2+}, \mathrm{Ga}^{3+}, \mathrm{In}^{3+}, \mathrm{Tl}^{3+}, \mathrm{SCN}^{-}, \mathrm{NO}_{3}{ }^{-} \mathrm{Cl}^{-}$ & $1: 25$ \\
\hline $\mathrm{Ag}^{+}, \mathrm{Pd}^{2+}, \mathrm{Pt}^{2+}, \mathrm{Rh}^{3+}, \mathrm{Hg}^{2+}, \mathrm{Br}^{-}, \mathrm{I}^{-}$ & $1: 18$ \\
\hline $\mathrm{V}^{5+}, \mathrm{Cr}^{3+}, \mathrm{Mn}^{2+}, \mathrm{Co}^{2+}, \mathrm{Zn}^{2+}, \mathrm{Cs}^{+}$ & $1: 14$ \\
\hline $\mathrm{Ni}^{2+}, \mathrm{Cd}^{2+}, \mathrm{Cu}^{2+}, \mathrm{Pb}^{2+}$ & $1: 10$ \\
\hline $\mathrm{EDTA}^{8+}$ disodiumtartrate, $\mathrm{Os}^{8+} \mathrm{W}^{6+}$ & Highly interfering \\
\hline
\end{tabular}

Table 3. Effect of Various Diverse Ions on the Extraction of W(VI) with Cyanex 923.

\begin{tabular}{|c|c|}
\hline Foreign Ions & Tolerance limit \\
\hline $\mathrm{Na}^{+}, \mathrm{Li}^{+}, \mathrm{K}^{+}, \mathrm{SO}_{4}{ }^{2-}$ & $1: 30$ \\
\hline $\mathrm{Al}^{3+}, \mathrm{Mg}^{2+}, \mathrm{Cd}^{2+}, \mathrm{In}^{3+}, \mathrm{SCN}^{-}, \mathrm{NO}_{3}{ }^{-}, \mathrm{Cl}^{-}$ & $1: 25$ \\
\hline $\mathrm{Th}^{3+}, \mathrm{Pd}^{2+}, \mathrm{Pt}^{2+}, \mathrm{Rh}^{3+}, \mathrm{Hg}^{2+}, \mathrm{Br}^{-}, \mathrm{I}^{-}$ & $1: 17$ \\
\hline $\mathrm{V}^{5+}, \mathrm{Cr}^{3+}, \mathrm{Ni}^{2+}, \mathrm{Cu}^{2+}, \mathrm{Zn}^{2+}, \mathrm{Cs}^{+}$ & $1: 10$ \\
\hline $\mathrm{Mn}^{2+}, \mathrm{Rh}^{3+}, \mathrm{Pb}^{2+}, \mathrm{Co}^{2+}$ & $1: 8$ \\
\hline $\mathrm{EDTA}^{2+} \mathrm{Fe}^{3+}, \mathrm{As}^{3+}, \mathrm{Mo}^{6+}$ & Highly interfering \\
\hline
\end{tabular}

\subsection{Separation of molybdenum (VI) and tungsten (VI) from multicomponent mixtures}

The separation of Mo(VI) and $\mathrm{W}(\mathrm{VI})$ from its mixtures and from multicomponent mixtures was achieved by exploiting the difference in their $\mathrm{pH}$ of extraction with varying concentration of Cyanex 923 in toluene and using different stripping agents (Table-4).

Table 4. Separation of Mo (VI) and W (VI) from multicomponent mixtures with Cyanex 923.

\begin{tabular}{|c|c|c|c|c|c|c|}
\hline $\begin{array}{c}\text { Sr. } \\
\text { No. }\end{array}$ & Mixture & $\begin{array}{c}\text { Amount } \\
\text { taken } \\
(\mu \mathrm{g} / \mathrm{ml})\end{array}$ & $\mathrm{pH}$ & $\begin{array}{c}\text { Cyanex 923 } \\
(\mathrm{M})\end{array}$ & Stripping Agent & $\begin{array}{c}\% \\
\text { Recovery }\end{array}$ \\
\hline \multirow{2}{*}{1.} & $\mathrm{Mo}(\mathrm{VI})$ & 50 & 2.5 & 0.005 & $0.1 \mathrm{M} \mathrm{NaOH}$ & 99.5 \\
\cline { 2 - 7 } & $\mathrm{W}(\mathrm{VI})$ & 50 & 2.5 & 0.005 & $0.5 \mathrm{M}\left(\mathrm{NH}_{4}\right)_{2} \mathrm{CO}_{3}$ & 99.6 \\
\hline \multirow{2}{*}{2.} & $\mathrm{Mo}(\mathrm{VI})$ & 25 & 2.5 & 0.005 & $0.1 \mathrm{M} \mathrm{NaOH}$ & 99.6 \\
\cline { 2 - 7 } & $\mathrm{Cr}(\mathrm{III})$ & 25 & 2.5 & 0.005 & Unextracted & 99.8 \\
\hline \multirow{2}{*}{3.} & $\mathrm{Mo}(\mathrm{VI})$ & 50 & 2.5 & 0.005 & $0.1 \mathrm{M} \mathrm{NaOH}$ & 99.6 \\
\cline { 2 - 7 } & $\mathrm{Zn}(\mathrm{II})$ & 25 & 8.0 & 0.005 & $1.0 \mathrm{M} \mathrm{HNO}_{3}$ & 99.2 \\
\cline { 2 - 7 } & $\mathrm{Ni}(\mathrm{II})$ & 25 & 8.0 & 0.005 & Unextracted & 99.3 \\
\hline \multirow{2}{*}{5.} & $\mathrm{~W}(\mathrm{VI})$ & 50 & 1.0 & 0.005 & $0.5 \mathrm{M} \mathrm{NH}_{4} \mathrm{CO}_{3}$ & 99.6 \\
\cline { 2 - 7 } & $\mathrm{Fe}(\mathrm{III})$ & 50 & 1.0 & 0.005 & Water & 99.5 \\
\cline { 2 - 7 } & $\mathrm{Cr}(\mathrm{III})$ & 25 & 1.0 & 0.005 & Unextracted & 99.3 \\
\hline \multirow{2}{*}{6.} & $\mathrm{~W}(\mathrm{VI})$ & 50 & 1.0 & 0.005 & $0.5 \mathrm{M}\left(\mathrm{NH}_{4}\right)_{2} \mathrm{CO}_{3}$ & 99.5 \\
\cline { 2 - 7 } & $\mathrm{Fe}(\mathrm{III})$ & 50 & 1.0 & 0.005 & Water & 99.5 \\
\cline { 2 - 7 } & $\mathrm{Ti}(\mathrm{IV})$ & 50 & 1.0 & 0.005 & Unextracted & 99.6 \\
\hline
\end{tabular}




\section{CONCLUSION}

1. The results obtained indicate that Cyanex-923 which is commercially available phosphine oxide, can be used for extraction for $\mathrm{Mo}(\mathrm{VI})$ and $\mathrm{W}(\mathrm{VI})$ at $\mathrm{pH} 2.5$ and 1.0 respectively with $5 \times 10^{-3}$ M Cyanex-923 extractant in toluene.

2. The extraction is complete unlike the extraction of Mo(VI) with triisodecylamine Alamine 310 which is very poor $(<8 \%)$.

3. The concentration of reagent required is very less $\left(5 \times 10^{-3} \mathrm{M}\right)$ as compared to the extraction of Mo(VI) using TBP which requires high concentrations $(1.5-2.0 \mathrm{M})$ of the reagent $[15-16]$.

\section{Acknowledgement}

The authors are thankful to Cytec Industries Inc, Canada for supplying the gift sample of Cyanex-923.

\section{References}

[1] K. C. Li, J. Met., June, (1962),413.

[2] A. K. De, S. M. Khopkar and R. B. Chalmers, Solvent extraction of metals, VNRCompany, London, (1970), 185.

[3] A. N. Zelikman, G. M. Vol'dman, N. N. Rakova, and T. P. Stenyushkina, Tsvet Metal, 45, (1972), 38.

[4] Y. Shuqiu and C. Jiayong, Acta Metall. Sin., 18, (1982), 187.

[5] F. Esnault, M. Robaylia, J. M. Latard, and J. M. Demarthe, Proceedings international Solvent Extraction Conference 1SEC74, Society of Chemical industry, London, 3, (1974), 2765.

[6] J. Robert and K. Zdenek, Solv. Extr. Ion Exch., 11(1), (1993), 33.

[7] J. J. Cruywagen, T. Rypstra, Polyhedron, 4(4), (1985), 545.

[8] R. N. Mohanty, S. Singh, V. Chakravortty and K. C. Dash, J. Radioanal. Nuci. Chem.,132, (1989), 35.

[9] R. N. Mohanty, S. Singh, V. Chakravortty and K. C. Dash, J. Radioanal. Nuci. Chem.,152, (1991), 21.

[10] A. Trujillo and H. Freiser, Solvent Extr. Ion Exch., 7(1), (1989), 1.

[11] A. Khoshnevisan, H. Yoozbashizadeh, M. Mohammadi, A. Abazarpoor and M. Maarefvand., Minerals and Metallurgical Processing, 30(1), (2013), 53.

[12] Vogel A. I., "A Text Book of Quantitative Inorganic chemical Analysis", Longman, London, (1975), $461 \& 471$.

[13] Z. Marczenko, Spectrophotometric Determination of Elements, Ellis, Horwood Chichester, (1976), $540 \& 580$. 
[14] R. G. Talla, S. U. Gaikwad and S. D. Pawar, Indian Journal of Chemical Technology, 17, (2010), 436.

[15] K. H. Arend and C. H. Specker, Z. Inorg. Aug. Chem., 18, (1964), 333.

[16] R. Jerger and Z. Kolarik, Sot. Ext. Ion Exch., 1, (1993), 33.

( Received 21 February 2015; accepted 02 March 2015 ) 